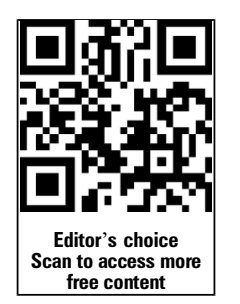

'Department of Pharmacy and Biotechnology, University of Bologna, Bologna, Italy ${ }^{2}$ Operative Unit of Medicine, Budrio Hospital, Budrio, Italy ${ }^{3}$ Department of Experimental, Diagnostic and Specialty Medicine, Cardiology Unit, University of Bologna,

Bologna, Italy

${ }^{4}$ Surgery Unit, Maggiore

Hospital, Bologna, Italy

${ }^{5}$ Medical Oncology

Department, Bellaria Hospital,

Azienda USL/ IRCCS Institute

of Neurological Sciences,

Bologna, Italy

${ }^{6}$ Anatomic Pathology Unit,

Maggiore Hospital, Bologna, Italy

${ }^{7}$ Endoscopy Unit, Maggiore Hospital, Bologna, Italy

${ }^{8}$ Department of Experimental, Diagnostic and Specialty

Medicine, School of Medicine, University of Bologna, Bologna, Italy

\section{Correspondence to}

Dr Dario de Biase, Department of Experimental, Diagnostic and Specialty MedicineUniversity of Bologna, Operative Unit Molecular Biology —Anatomic Pathology -Bellaria Hospital, Via Altura 3, Bologna 40139, Italy; dario.debiase@unibo.it

Received 1 July 2015 Revised 4 August 2015 Accepted 5 August 2015 Published Online First 27 August 2015

\section{CrossMark}

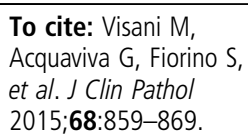

\title{
Contribution of microRNA analysis to characterisation of pancreatic lesions: a review
}

\author{
Michela Visani, ${ }^{1}$ Giorgia Acquaviva, ${ }^{1,8}$ Sirio Fiorino, ${ }^{2}$ Maria Letizia Bacchi Reggiani, ${ }^{3}$ \\ Michele Masetti, ${ }^{4}$ Enrico Franceschi, ${ }^{5}$ Adele Fornelli, ${ }^{6}$ Elio Jovine, ${ }^{4}$ Carlo Fabbri, ${ }^{7}$ \\ Alba A Brandes, ${ }^{5}$ Giovanni Tallini, ${ }^{8}$ Annalisa Pession, ${ }^{1}$ Dario de Biase ${ }^{1,8}$
}

\section{ABSTRACT}

Pancreatic tumours are usually very aggressive cancer with a poor prognosis. A limitation of pancreatic imaging techniques is that lesions are often of ambiguous relevance. The inability to achieve a definitive diagnosis based on cytological evaluation of specimens, due to sampling error, paucicellular samples or coexisting inflammation, might lead to delay in clinical management. Given the morbidity associated with pancreatectomy, a proper selection of patients for surgery is fundamental. Many studies have been conducted in order to identify specific markers that could support the early diagnosis of pancreatic lesions, but, to date, none of them allow to diagnose pancreatic cancer with high sensitivity and specificity. MicroRNAs (miRNA) are small non-coding RNAs (19-25 nucleotides) that regulate gene expression interacting with mRNA targets. It is now established that each tissue shows a characteristic miRNA expression pattern that could be modified in association with a number of different diseases including neoplasia. Due to their key role in the regulation of gene expression, in the last years several studies have investigated miRNA tissue-specific expression, quantification and functional analysis to understand their peculiar involvement in cellular processes. The aim of this review is to focus on miRNA expression in pancreatic cancer and their putative role in early characterisation of pancreatic lesions.

\section{INTRODUCTION}

The diagnosis of pancreatic cancer (PC) is still a troubled issue. Patients often present with nonspecific symptoms, which contribute to delay in correct diagnosis. A limitation of pancreatic imaging technique is that lesions are often of ambiguous relevance: a high-grade mass could be indistinguishable from a chronic pancreatitis (CP) or from a benign pancreatic cyst. The definitive diagnosis based on cytological evaluation of specimens obtained by endoscopic ultrasound-guided fine needle aspiration (EUS-FNA) might be sometimes inconclusive due to, for example, sampling error, paucicellular samples or coexisting inflammation. The inability to achieve a cytological diagnosis might lead to delay in clinical management. ${ }^{12}$

For these reasons, many studies have been performed in order to identify specific markers that could support the diagnosis of pancreatic lesions as the most aggressive pancreatic ductal adenocarcinoma (PDAC), PDAC precursor lesions (eg, intraductal papillary mucinous neoplasia (IPMN)), pancreatic intraepithelial neoplasia (PanIN) or mucinous cystic neoplasms (MCNs)). ${ }^{1}$

Several molecular markers altered in pancreatic lesions have been described. For example, mutations in KRAS or TP53 genes have been reported in $95 \%$ and $70 \%$ of PDACs, respectively. KRAS mutations have also been reported in $50 \%$ of IPMN, MCN and PanIN-1 cases, suggesting that it could be an early event in malignant transformation. ${ }^{2-5}$ Also, the inactivation of $C D K N 2 A / p 16$ or SMAD4/ DPC4 genes are frequent molecular alterations in PDAC. ${ }^{12}$ An intermediate event in pancreatic carcinogenesis could be represented by the inactivation of $C D K N 2 A / p 16$, found in PanIN-2 and IPMN. ${ }^{2-5}$ The inactivation of TP53, SMAD4/DPC4 and BRCA2 is reported in PanIN-3 cases and hypothesised as late molecular events in tumour progression. $^{2-5}$

In spite of interesting findings, to date there are no molecular markers that allow us to characterise and diagnose each pancreatic lesion with high specificity and sensitivity. MicroRNAs (miRNA) are small (19-25 nucleotides) non-coding RNA molecules that negatively regulate gene expression by degrading or suppressing the protein translations of mRNA targets. Due to their key role in the regulation of gene expression, in the last years, expression, quantification and their functional role had been deeply investigated to understand their involvement in cellular processes. It is now established that each tissue harbour a characteristic miRNAs expression pattern that could be modified in association with a number of different diseases, including neoplastic transformation. ${ }^{6-9}$ For these characteristics and for their resistance to nucleic acid degradation, miRNAs could represent intriguing cancer biomarkers. Several studies have been conducted in order to characterise miRNA expression in pancreatic lesions. ${ }^{10}$ The highest number of these works were focused on PDAC, while less studies investigated miRNA expression in cystic lesions and other pancreatic diseases, such as solid-pseudopapillary tumours of the pancreas (SPPTs) or pancreatic neuroendocrine tumours (PanNETs).

Beyond the specific characterisation of each pancreatic diseases, the crucial issue for clinical management might be the identification of specific circulating miRNAs (eg, in blood, serum, plasma, pancreatic fluid, bile) that could be used for early diagnosis of pancreatic lesion.

The aim of this review is to report about miRNA expression in pancreatic tumours and, in 
particularly, focus the attention on specific circulating miRNAs that could be used for early characterisation of pancreatic lesions.

\section{STARTING MATERIAL AND TECHNIQUES Starting material}

Material for analysis of molecular biomarkers could be obtained directly from the investigated pancreatic lesion or it could be extracted from extralesional material (eg, plasma, sera, pancreatic juice) (table 1).

\section{Lesional material (fresh/frozen and FFPE specimens)}

Surgical resection remains the only potentially curative treatment for pancreatic adenocarcinoma, but it is associated with a high rate of complications, morbidity and mortality. ${ }^{11}$ The limitation of 'fresh' pancreatic tissue for analysing miRNAs as biomarkers is an extremely invasive procedure for collecting material. In fact, if, on the one hand, fresh/frozen (non-formalin fixed) specimens allow us to obtain a good amount of smallRNA (sRNA) for miRNA analysis, on the other hand, their availability from surgical samples is limited, considering that the material for diagnostic evaluation needs to be preserved. For this reason, the analysis of miRNAs starting from formalin-fixed paraffin-embedded (FFPE) specimens could provide a greater amount of material for research purposes (see below). Different studies were performed for analysing miRNA expression starting from fresh/frozen pancreatic tissue resected for pancreatic lesions. ${ }^{12-24}$

Another frequent 'non-formalin fixed' starting material is represented by pancreatic cytological specimens, obtained with EUS-FNA. ${ }^{25}$ In a paper by Hong and Park, ${ }^{26}$ the authors demonstrated the feasibility of performing miRNA analysis on specimens obtained using FNA. Szafranska $e a^{27}$ reported that miRNA analysis from fresh FNA biopsy samples differentiated malignant from benign PC tissue. The analysis of cystic mass

Table 1 Summary of starting material and techniques used for miRNA characterisation in pancreatic lesions

\begin{tabular}{|c|c|c|c|}
\hline $\begin{array}{l}\text { Starting } \\
\text { material }\end{array}$ & Technique* & $\begin{array}{l}\text { Number of } \\
\text { studies }\end{array}$ & References \\
\hline \multicolumn{4}{|l|}{ Lesional } \\
\hline \multirow[t]{2}{*}{ Fresh/frozen } & Microarray & 9 & $16,17,21-24,26,29,30$ \\
\hline & Real time & 11 & $12-15,18-20,26-28,31$ \\
\hline \multirow[t]{3}{*}{ FFPE } & Microarray & 8 & $39,40,43,45-48,54$ \\
\hline & Real time & 12 & $28,40,41,43,44,49,50,51,53,55,56,58$ \\
\hline & ISH & 2 & 51,56 \\
\hline \multicolumn{4}{|c|}{ 'Extralesional'-peripheral } \\
\hline \multirow[t]{2}{*}{ Pancreatic juice } & Real time & 4 & $19,31,53,61$ \\
\hline & Microarray & 1 & 62 \\
\hline Bile & Real time & 1 & 61 \\
\hline Stool & Real time & 1 & 19 \\
\hline \multirow[t]{2}{*}{ Blood } & Real time & 1 & 66 \\
\hline & Microarray & 1 & 21 \\
\hline \multirow[t]{2}{*}{ PBMC } & Real time & 1 & 67 \\
\hline & NGS & 1 & 68 \\
\hline \multirow[t]{2}{*}{ Plasma } & Microarray & 1 & 69 \\
\hline & Real time & 6 & $61,70,71,73,76,77$ \\
\hline \multirow[t]{3}{*}{ Serum } & Real time & 4 & $72,78-80$ \\
\hline & Microarray & 1 & 75 \\
\hline & NGS & 1 & 74 \\
\hline
\end{tabular}

*Only the main technique used in the study has been reported.

FFPE, formalin-fixed paraffin-embedded; ISH, in situ hybridisation; miRNA, microRNA; NGS, next-generation sequencing; PBMC, peripheral blood mononuclear cells. usually is based on the evaluation of cystic liquid. Specific miRNAs identified in cysts fluid could aid in diagnosis and surgical treatment decisions for patients with pancreatic cystic lesions. ${ }^{28}$ Other studies have analysed cystic fluid to identify potential biomarkers for the classification of cystic lesions ${ }^{29}$ or to distinguish between benign and premalignant or malignant pancreatic lesions. ${ }^{30} 31$

Starting from FFPE samples might be of great use for miRNA expression studies. Due to their short length, the mature miRNAs seem not to be influenced by nucleic acid degradation caused by formalin fixation, ${ }^{32}$ as happened on the contrary for long RNA or DNA. Several papers reported the feasibility of miRNA expression from FFPE specimens in different tissues as kidney, ${ }^{33}$ prostate, ${ }^{34}{ }^{35}$ breast $^{36}$ and brain. ${ }^{37}$ Also for pancreatic lesions, several papers have analysed miRNA expression profile in FFPE specimens compared with non-neoplastic or benign tissue, obtaining robust and reliable results. ${ }^{28} 3038-58$

\section{'Extralesional' material}

For cytological evaluation of pancreatic lesions, pancreatic juice could be used. ${ }^{59} 60$ The identification of molecules, such as miRNAs or proteins, in pancreatic juice might be useful for early detection of pancreatic lesions. For this reason, some studies have investigated the expression profile of pancreatic juice in pancreatic lesions compared with that of $\mathrm{CP}$ and healthy controls. ${ }^{19} 3153 \quad 6162$ Considering that patients with PDAC usually present with bile duct obstruction, Cote $e t a^{61}$ looked for miRNAs also in bile of patients with PDAC. According to Yang et $a l,{ }^{19}$ most of the body fluid used for investigating biomarker analysis suffered from significant limitations such as lack of methodological standardisation and quality control. Therefore, they proposed miRNA expression analysis in stool as stable, non-invasive and high-sensitivity/high-specificity screening test for pancreatic lesions. It should be also considered that selection of miRNAs to analyse in body fluid (eg, bile or plasma) on the basis of their expression in pancreatic tumoral tissue may not reflect the real 'circulating miRNA profile' ${ }^{63}$ In fact, it has been observed that several miRNAs may have different expression profiles in tissue and body fluid. ${ }^{21}$ To avoid 'selection bias', it should be preferable using a discovery microarray assay to profile miRNAs in body fluid, as previously suggested by Le Large and colleagues. ${ }^{63}$

The identification of circulating markers for early diagnosis and classification could be very useful in the management of pancreatic lesions, and miRNAs could represent a very promising molecular target. MiRNAs are very stable in blood because they are bound with Argonaute protein, a molecule that protects them from RNase degradation. ${ }^{64} 65$

Different studies report the presence of deregulated miRNAs in whole blood of patients with pancreatic lesions with the potential to discriminate patients with PC from healthy control, patients with pancreatitis or suspected of having PC. ${ }^{21}{ }^{66}$ It has been reported that patients with cancer (or subjects with a high risk of developing cancer) have alteration of normal epigenetics mechanisms in their peripheral blood mononuclear cells (PBMCs).$^{60}$ For this reason, two papers focused their studies on circulating (PBMCs) expression of miRNA. ${ }^{67} 68$ To avoid miRNA 'contamination' due to blood cells, several other studies looked for miRNA profile not in whole blood but in serum and plasma of patients with pancreatic lesions. ${ }^{61}{ }^{69-80}$

\section{Techniques}

Analysis of miRNAs with high specificity and sensitivity is technically challenging as mature miRNAs are short molecules, differ 
in guanine-cytosine (GC) content and single-nucleotide difference within miRNA families. Several techniques based on extracted RNA (deep/parallel sequencing, oligonucleotide microarrays, quantitative real-time (qRT)-PCR detection of miRNAs) or in situ hybridisation (ISH) assays have made possible to profile miRNAs in pancreatic lesions with high accuracy (table 1).

\section{qRT-PCR}

The most frequent method used for assessing miRNA expression

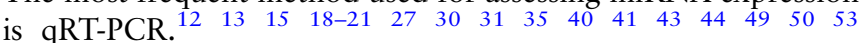
$\begin{array}{lllllllll}55 & 56 & 58 & 61 & 66 & 67 & 70-74 & 76-80\end{array}$

Several approaches to analyse miRNAs continue to be based on single-gene assays; however, high-throughput technologies can be employed to identify differences in miRNA expression levels between normal and cancerous tissues. These methods have the potential to identify hundreds of differentially expressed miRNAs. For example, TaqMan low-density arrays and locked nucleic acid array platform have been introduced for miRNA detection. They are based on the same principles of qRT-PCR but offer higher throughput than standard PCR, allowing us to analyse a huge number of miRNAs in a single plate of amplification. ${ }^{26} 285181$

\section{Microarray}

Microarray technology is a powerful high-throughput tool that allows monitoring the expression of thousands of sRNAs at once processed in parallel in a single experiment. Several papers have been based on a genome-wide analysis of miRNA expression of normal and lesional pancreatic specimens to distinguish expression signatures and associate this profile with diagnosis, prognosis or therapeutic interventions. ${ }^{16} \quad \begin{array}{llllll}17 & 21-24 & 26 & 29 & 30 & 38\end{array}$ $394245-485462697578$ It should be considered that a big limitation of microarray analysis is that the results need to be validated using a targeted technique, as qRT-PCR or ISH assays (see below).

\section{Next-generation sequencing}

Deep sequencing strategies allow us to analyse thousands of sequences in parallel from a given sample and could highlight both miRNAs present in few copies and discover novel miRNAs without the limitation of microarray probe selection. This approach in pancreatic lesions has been performed by two studies that investigated miRNA expression profiles in serum of 25 patients with PC compared with 25 healthy controls ${ }^{74}$ or in PBMCs in a large cohort of 352 participants. ${ }^{68}$

\section{In situ hybridisation}

A limitation of the previously described techniques is that they are based on extracted sRNA and then do not provide information regarding the cell type present in the sample and the specific site of expression of a particular miRNA. Thus, the use of a combined ISH/immunohistochemistry assay enables rapid and direct evaluation of changes of miRNA expression within the suspicious cells. In situ techniques are used either as main assay for evaluating miRNA expression in pancreatic lesions visualised at cellular/subcellular level ${ }^{525768}$ or to confirm results obtained by qRT-PCR or high-throughput technique (eg, miRNA microarray or real-time array). ${ }^{304143}$

\section{MIRNAs DEREGULATED IN SOLID LESIONS Pancreatic ductal adenocarcinoma}

PDAC is a highly lethal neoplasia. Most PDAC cases are diagnosed too late when surgical resection cannot be performed for the advanced stage of the lesion, often characterised by vascular dissemination and lymph node involvement. Both the lack of early symptoms and not specific late symptoms contribute to delay the correct diagnosis. ${ }^{27} 82$

New biomarkers are clinically necessary in PDAC management to help the diagnosis, guide therapeutic options, discriminate PDAC from other pancreatic lesions (eg, CP) and monitor relapse after treatment.

miRNAs, for their stability and tissue specificity expression, are appealing biomarkers useful to characterise neoplasias and to create specific diagnostic panels. In the last years, different research approaches have studied miRNA expression profiling of PDAC, starting from fresh/frozen and FFPE tissues with the aim to describe the biological aspect of neoplasia, or starting from blood/serum or other body fluids with the aim to identify suitable markers for early diagnosis.

High-throughput analysis based on microarray or nextgeneration sequencing or targeted approaches through RT-PCR technique identified miRNA signatures that were able to precisely classify tumours and differentiate PDAC from normal pancreas and pancreatitis.

\section{Profiling studies}

In table 2, miRNA profiling studies performed on PDAC tissues are reported. In many miRNA PDAC profiling studies, researchers enrolled both normal pancreatic samples and CP specimens as control. CP could mimic a pancreatic tumour, morphologically and clinically, sharing many differentially expressed proteins or miRNAs. For this reason, it is clinically relevant adopting markers could specifically discriminate CP from a more aggressive lesion like PDAC. ${ }^{83}$

In the work by Bloomston et al, ${ }^{39}$ the authors have analysed 65 FFPE paired cases of PDAC and normal pancreatic tissues and identified 21 miRNAs upregulated and 4 miRNAs downregulated in PDAC. Evaluating miRNA expression in 42 cases of CP, they found 15 miRNAs upregulated (miR-96, miR-221, miR-34, miR-497, miR-203, miR-155, miR-181a, miR-453, miR-92, miR-181b, miR-181d, miR-93, miR-181b-1，miR-21 and miR-181c) and 8 miRNAs downregulated (miR-494, miR-483, miR-339, miR-218, miR-148a, miR-375, miR-409 and miR-148b). Expression of all these miRNAs allowed to differentiate PC from CP with 93\% accuracy. ${ }^{39}$ Szafranska et al ${ }^{22}$ reported the expression of several miRNAs (miR-29c, miR-96, miR-141, miR-148b, miR-143, miR-145, miR-146a, miR-150, miR-155 and miR-223) deregulated in both pancreatitis and cancer samples compared with normal tissues. Differently to what was observed by Bloomston et al, miR-96, miR-148b and miR-155 were not observed as deregulated between PDAC and $\mathrm{CP}^{22}$ Bloomston et al demonstrated, using miRNA microarray, that upregulation of miR-155, miR-181a, miR-181b, miR-181b-1, miR-181c, miR-181d, miR-21 and miR-221, as well as downregulation of miR-148a, mir-148b and miR-375, could specifically distinguish PDAC from normal pancreas and pancreatitis samples. On the other hand, Szafranska et al, ${ }^{22}$ using the same high-throughput approach (miRNA microarray), concluded that miR-196a, miR-196b, miR-203, miR-210, miR-222, miR-216, miR-217 and miR-375 were misregulated only in PDAC samples and not in CP or healthy subjects. Interestingly, nevertheless in both papers the same technique has been used, only one miRNA (miR-375) has been observed deregulated (downregulated) in PDAC in the two studies. These data show that it is not easy to obtain consistent results in miRNA analysis also using the same molecular methods.

In a subsequent work performed on frozen samples using a targeted miRNA approach, Szafranska et $a l^{27}$ observed as upregulated miR-196a, miR-155, miR-143, miR-145, miR-223, 
Table 2 Profiling studies on PDAC tissues

\begin{tabular}{|c|c|c|}
\hline miRNAs upregulated & miRNAs downregulated & References \\
\hline $\begin{array}{l}\text { miR-155, miR-181a, miR-181b, } \\
\text { miR-181b-1, miR-181c, } \\
\text { miR-181d, miR-21, miR-221 }\end{array}$ & miR-148a, miR-148b,miR-375 & $39 \S$ \\
\hline $\begin{array}{l}\text { miR-196a, miR-196b, miR-203, } \\
\text { miR-210, miR-222 }\end{array}$ & miR-216, miR-217, miR-375 & $22 \S$ \\
\hline $\begin{array}{l}\text { miR-196a, miR-155, miR-143, } \\
\text { miR-145, miR-223, miR-31 }\end{array}$ & $\begin{array}{l}\text { miR-96, miR-130b, miR-148a, } \\
\text { miR-217, miR-375 }\end{array}$ & $27 \S$ \\
\hline $\begin{array}{l}\text { miR-196a, miR-221, miR-222, } \\
\text { miR-15b, miR-95, miR-186, } \\
\text { miR-190, miR-200b }\end{array}$ & & 20 \\
\hline $\begin{array}{l}\text { miR-155, miR-203, miR-210, } \\
\text { miR-222 }\end{array}$ & miR-216, miR-217 & $12+$ \\
\hline $\begin{array}{l}\text { miR-21, miR-27a, miR-146a, } \\
\text { miR-200a, miR-196a }\end{array}$ & miR-217,miR-20a, miR-96 & 26 \\
\hline $\begin{array}{l}\text { miR-221, miR-181a, miR-181c, } \\
\text { miR-155,miR-21, miR-100 }\end{array}$ & miR-375 & 13 \\
\hline $\begin{array}{l}\text { miR-21, miR-221, miR-100, } \\
\text { miR-155, miR-181b,miR-196a }\end{array}$ & & 49 \\
\hline $\begin{array}{l}\text { miR-21, miR-155, miR-210, } \\
\text { miR-221, miR-222 }\end{array}$ & $\begin{array}{l}\text { miR-31, miR-122, miR-145, } \\
\text { miR-146a }\end{array}$ & 50 \\
\hline $\begin{array}{l}\text { miR-223, miR-143, miR-27a, } \\
\text { let-7i, miR-21, miR-145, } \\
\text { miR-142-5p, miR-142-3p, } \\
\text { miR-10a, miR-150, miR-214, } \\
\text { miR-146b-5p, miR-107, } \\
\text { miR-100, miR-23a, } \\
\text { miR-199a-5p, miR-222, } \\
\text { miR-103, miR-155, miR-221, } \\
\text { miR-34a, miR-130a, } \\
\text { miR-331-3p, miR-24, miR-505 }\end{array}$ & $\begin{array}{l}\text { miR-30d, miR-381, miR-29c, } \\
\text { miR-324-3p, miR-874, miR-30a, } \\
\text { miR-33b*, miR-30c-1 }{ }^{*} \\
\text { miR-139-3p, miR-887, miR-141, } \\
\text { miR-575, miR-28-3p, miR-665, } \\
\text { miR-494, miR-617, miR-564, } \\
\text { miR-148a, miR-130b, miR-217, } \\
\text { miR-708, miR-648, miR-148b, } \\
\text { miR-345, miR-216a }\end{array}$ & $23 \neq$ \\
\hline $\begin{array}{l}\text { miR-23a, miR-103, miR-107, } \\
\text { miR-1207-5p, miR-125a-5p, } \\
\text { miR-221, miR-140-5p, } \\
\text { miR-143, let-7d, miR-146, } \\
\text { miR-145, let-7e, miR-199b-3p, } \\
\text { miR-199a -3p, miR-138-1*, } \\
\text { miR-92b, miR-29b-1*, } \\
\text { miR-92 }{ }^{*} \text {, miR-181, miR-1246, } \\
\text { miR-31, let-7,miR-155, } \\
\text { miR-26a, miR-17, miR-23b, } \\
\text { miR-24, miR-500*,miR-331-3p, } \\
\text { miR-939 }\end{array}$ & $\begin{array}{l}\text { miR-1254, miR-559, let-7f-1 * } \\
\text { miR-1274a }\end{array}$ & 24 \\
\hline miR-132, miR-212 & & 15 \\
\hline $\begin{array}{l}\text { miR-372, miR-146a, miR-204, } \\
\text { miR-10a, miR-10b }\end{array}$ & & 58 \\
\hline miR-21, miR-196a & miR-148a, miR-217 & $55 \S$ \\
\hline
\end{tabular}

miR-31 and miR-96, miR-130b, miR-148a, miR-217 and miR-375 as downregulated specifically in PDAC samples compared with normal pancreatic tissues and CP. According to the obtained results, the authors hypothesised using a 2-miRNA classifier (miR-196a and miR-217), whose expression levels could discriminate PDAC from normal pancreas and CP, suggesting a fast and easy miRNA assay for early discrimination of PDAC. $^{27}$

The upregulation of miR-196a observed by Szafranska et $a l^{27}$ was detected also by Zhang and colleagues analysing 95 miRNAs in $10 \mathrm{PC}$ cell lines and 17 pairs of $\mathrm{PC} /$ normal tissues. ${ }^{20}$ In the present paper, the authors also report the upregulation of other seven miRNAs (miR-15b, miR-95, miR-186, miR-190, miR-200b and miR-221/222). ${ }^{20}$
Other papers reported miRNAs deregulated in PDAC specimens. For example, the screening of miRNA expression in 56 microdissected PDAC cases identified as upregulated miR-155, miR-203, miR-210 and miR-222 and downregulated miR-216 and miR-217. ${ }^{12}$

A paper by Hong and Park $^{26}$ reported the upregulation of miR-21, miR-27a, miR-146a, miR-200a and miR-196a from fresh surgical specimens. In the same work, they confirmed the lower expression in PDAC samples of miR-217 together with miR-20a and miR-96. ${ }^{26}$ Lee et $a l^{13}$ identified several miRNAs upregulated or downregulated in pancreatic carcinoma compared with normal tissue, most of them reported also by Bloomston et al: ${ }^{39}$ miR-221, miR-181a and miR-181c, miR-155 and miR-21 were upregulated, whereas miR-375 was downregulated. ${ }^{13}$ In addition, they indicated an upregulation of miR-100, in accordance with results of Panarelli et $a l^{49}$ In the latter paper, the authors also observed the upregulation of miR-21, miR-221, miR-155 and miR-181b in PDAC samples relative to normal pancreas and an upregulation of miR-21, miR-221, miR-155 and miR-181b in PDAC also if compared to IPMN. ${ }^{49}$

Xue et al measured the expression levels of miR-148a, miR-217, miR-21, miR-196a and miR-10b in PDAC towards benign pancreatic parenchyma and CP. In this work, miR-21 and miR-196a were significantly upregulated, while miR-148a and miR-217 expression levels were downregulated in PDAC. ${ }^{55}$

While the profiling studies cited earlier were performed on PDAC tissues or cell line, other works reported in table 3 were based on miRNA detection in blood, serum, plasma, bile, pancreatic juice or stool. The main aim of these studies was to discover potential PDAC biomarkers in body fluids to set-up a specific miRNA panel that could be applied as early diagnostic test. These papers will be deeply discussed in the section 'miRNA in early detection of pancreatic lesions'.

Briefly, two studies identified miRNA signature in PDAC compared with CP and normal specimens. ${ }^{6178}$ According to these studies, the analysis of five miRNAs (miR-10b, miR-106b, miR-30c, miR-155 and miR-212) ${ }^{61}$ or the expression of only

Table 3 PDAC profiling studies performed on blood, serum, plasma, bile, pancreatic juice or stool

\begin{tabular}{lll}
\hline miRNAs upregulated & $\begin{array}{l}\text { miRNAs } \\
\text { downregulated }\end{array}$ & References \\
\hline $\begin{array}{l}\text { miR-205, miR-210, miR-492, miR-1247 } \\
\text { miR-10b, miR-155, miR-106b, miR-30c, }\end{array}$ & 62 \\
miR-212 & 61 \\
miR-27a-3p, miR-16-5p, miR-15-5p & \\
miR-21, miR-210, miR-155, miR-196a & 68 \\
miR-20a, miR-21, miR-24, miR-25, & 77 \\
miR-99a, miR-185, miR-191 & $74 \S$ \\
miR-26b, miR-34a, miR-122, miR-126*, & \\
miR-145, miR-150, miR-223, miR-505, & \\
miR-636, miR-885.5p & $66 \dagger$ \\
miR-16, miR-21, miR-155, miR-181a, & \\
miR-181b, miR-196a, miR-210 & \\
miR-21 & & $73 \S$ \\
miR-21, miR-155 & \\
miR-18a & & $78 \S$ \\
miR-221 & & 53 \\
miR-21, miR-155 & & 76 \\
\hline
\end{tabular}

$\S$ miRNAs differently expressed in PDAC and CP.

tmiR-150, miR-636, miR-145 and miR-223 are sufficient to identify PDAC lesions.

$\mathrm{CP}$, chronic pancreatitis; miRNA, microRNA; PDAC, pancreatic ductal adenocarcinoma. 
one miRNA (miR-21) (Kong et $a l^{78}$ ) is sufficient to discriminate PDAC from CP and controls. Some of the miRNAs (miR-181a, miR-181b, miR-221 and miR-222) observed deregulated in PDAC tissues $^{12} 132022-24394950$ were instead not detected as deregulated in sera of subjects with PDAC. ${ }^{78}$ The upregulation in serum of two miRNAs (miR-155 and miR-196a) upregulated in PDAC tissues ${ }^{12} 13 \quad 2022-24 \quad 2627394950$ could discriminate sick pancreas (PDAC and $\mathrm{CP}$ ) from healthy controls but were not able to discriminate PDAC from $\mathrm{CP}^{78}$

\section{PDAC miRNA signature panel}

According to the above-reported studies, we tried to identify a miRNA signature panel for PDAC (table 4).

Considering miRNAs found significantly deregulated in at least three studies, in this hypothetical panel, the upregulated PDAC miRNAs would be the following: miR-21, miR-24, miR-27a， miR-100， miR-143， miR-145， miR-146， miR-155, miR-181a, miR-181b, miR-196a, miR-210, miR-221, miR-222 and miR-223. In the same theoretical panel, the downregulated miRNAs would be the following: miR-148a, miR-216, miR-217 and miR-375.

All these miRNAs were reported as deregulated in PDAC also in the meta-analysis by $\mathrm{Ma}$ and colleagues. ${ }^{84} \mathrm{In}$ this study, the authors performed an extensive literature search for studies comparing non-tumoral pancreatic specimens to PDAC using microarray techniques and have reported the miRNAs observed deregulated in at least two studies. As previously described by Frampton et $a l,{ }^{85}$ using a robust rank aggregation methods Ma and colleagues detected that 10 miRNAs are significantly deregulated in PDAC in comparison to normal controls (miR-21, miR-23a, miR-31, miR-100, miR-143, miR-155 and miR-221 were upregulated; miR-148a, miR-217 and miR-375 were downregulated). 8485

It should be considered that deregulation of miR196a, miR-148a and miR-217 seems to be not specific for PDAC: in fact, Xue and colleagues detected these miRNAs deregulated also in PanIN II-III compared with the normal pancreatic parenchyma. Moreover, miR-145 and miR-146, usually upregulated in PDAC, 2324262758 were detected as downregulated in one paper by Papacostantinou and colleagues. ${ }^{50}$ Upregulation of miR-21, which seems to be specific of PDAC, ${ }^{13} 2326394950$ has been hypothesised as an early event during malignant transformation from normal pancreatic tissue. ${ }^{45}$ Interestingly, the authors observed miR-21 downregulated in PDAC if compared to pancreatic benign cystic tumours, like serous microcystic adenoma. ${ }^{45}$

Table 4 miRNA profile in PDAC reported in at least three studies

\begin{tabular}{ll}
\hline Upregulated miRNAs & Downregulated miRNAs \\
\hline miR-21 & miR-148a \\
miR-24 & miR-216 \\
miR-27a & miR-217 \\
miR-100 & miR-375 \\
miR-143 & Discordant miRNAs* \\
miR-155 & miR-145 \\
miR-181a & miR-146a \\
miR-181b & \\
miR-196a & \\
miR-210 & \\
miR-221 & \\
miR-222 & \\
miR-223 & \\
\hline *miRNA reported with discordant pattern between different studies. \\
miRNA, microRNA; PDAC, pancreatic ductal adenocarcinoma.
\end{tabular}

Prognostic miRNAs in PDAC

We further investigate whether some of the above-reported miRNAs have been correlated in literature with prognosis of PDAC. For example, expression analysis of miR-196a, found to be upregulated in PDAC, 202226274955 allowed to distinguish long-term PDAC from short-term ones. ${ }^{39}$ Moreover, miR-196a has been indicated as a potential marker of poor prognosis and for clinical management in laparotomy decision (see the section 'miRNA in early detection of pancreatic lesions').

Profiling study, performed in 48 fresh/frozen PDAC samples, identified that poor prognosis PDAC was significantly associated with low expression of miR-29c, miR-30d, miR-34a and/or high expression of miR-21, miR-221 and miR-224. ${ }^{23}$ The authors reported that the expression levels of miR-21 and miR-146a were correlated with tumour stage, grade and lymph node status. $^{23}$ The prognostic role of miR-21 was highlighted also by Papaconstantinou et al: in a cohort of 88 FFPE PDAC samples, the higher expression levels of miR-21 and miR-155 were associated with tumour stage and poor prognosis. ${ }^{50}$ Differently to what was observed by Jamieson and Papaconstantinou, Dillhoff et al, using an ISH technique, showed that high levels of miR-21 were not associated with tumour size, grade, differentiation or lymph node implication. However, considering a subgroup of patients with node-negative disease, high levels of miR-21 were correlated with poor prognosis (ie, shorter survival). ${ }^{57}$ The poor predictive values of $\mathrm{miR}-155,{ }^{50}$ together with miR-210 and miR-222, were reported also by Greither et $a l .{ }^{12}$ These authors have observed that the higher expression of these three miRNAs was associated with an increased risk of tumour-related death. ${ }^{12}$

In accordance with those reported by Jamieson et al, ${ }^{23}$ Kawaguchi et $a l^{71}$ showed that high plasma miR-221 concentration could be a diagnostic and prognostic PDAC marker. They demonstrated its association with a poorer outcome, characterised by unresectable status and the presence of distant metastasis. $^{71}$

Prognostic role of some of these miRNAs (ie, miR-21, miR-155, miR-196a, miR-222 and miR-34a) has been deeply illustrated by Frampton et $a l^{86}$ in a systematic review and meta-analysis focused on the impact of miRNAs on overall survival (OS) and disease-free survival in PDAC. In this study, the authors estimated the HR per each investigated miRNAs and concluded that miR-21 is a strong predictor of OS in resected PDAC (HR 2.72). The other miRNAs deregulated in PDAC with prognostic significance were miR-155 (upregulated, HR 2.08), miR-203 (upregulated, HR 2.30) and miR-34 (downregulated, HR 4.27). ${ }^{86}$

\section{Solid pseudopapillary and neuroendocrine tumours}

SPPTs are rare, accounting for 1-2\% of exocrine pancreatic neoplasia. $^{87}$ Differently from PDAC, alterations in KRAS, TP53, CDKN2A and SMAD4 genes have not been reported in SPPT, while they usually harbour somatic mutation in CTNNB1 gene (encoding for $\beta$-catenin protein). To date, miRNA expression in SPPT has been investigated by only few papers. In a study by Park et al, performed on 14 SPPTs, 49 miRNAs were upregulated and 30 downregulated. These miRNAs specifically distinguish pancreatic SPPT from PDAC or NETs. ${ }^{16}$ Six miRNAs (miR-429, miR-7-5p, miR200b-3p, miR-192-3p, miR200b-5p and miR-200a-3p) were downregulated in SPPT but their expression was increased in PDAC and/or NET. ${ }^{16}$ According to the authors, the miR-200bc/429, miR-192/215 and miR-141/ $200 \mathrm{a}$ families contribute to upregulating $\mathrm{Wnt} / \beta$-catenin, Hedgehog and androgen receptor pathway gene expression in 
pancreatic SPPT. ${ }^{16}$ Another study on SPPT reported that miR-21, previously described as upregulated in PDAC (see section 'Pancreatic ductal adenocarcinoma'), is upregulated also in SPPT compared with serous cystoadenoma. ${ }^{28}$

PanNETs may occur sporadically or as part of multiple endocrine neoplasia type 1 syndrome. The malignant potential among PanNETs varies greatly and cannot be predicted on the basis of histological appearance. MiR-103 was the best discriminator for comparisons of normal pancreas and endocrine tumours. The expression of miR-107 and the significant upregulation in tumours versus controls of miR-23a, miR-26b, miR-192 and miR-342 was also reported. Among the downregulated miRNAs in PanNET, northern blot of miR-155 showed the lack of detectable expression of this miRNA in endocrine tumours. ${ }^{17}$ Moreover, also PanNET, as PDAC, showed upregulation of miR-21, and this is associated with high Ki67 proliferation index and the presence of liver metastasis. ${ }^{17}$ Matthaei and colleagues, in a study performed on five PanNETs, identified nine miRNAs (miR-18a, miR-24, miR-30a, miR-92a, miR-99b, miR-106b, miR-142, miR-342 and miR-532) that are able to discriminate PanNET cystic form from other pancreatic cystic lesions. ${ }^{28}$

\section{MIRNA DEREGULATED IN CYSTIC LESIONS}

Cystic tumours of the pancreas are a group of diseases with variable malignant potential and are often either benign or lowgrade indolent neoplasia (eg, pseudocysts). However, those that are mucinous (IPMN and MCN) constitute an important category with malignant potential. ${ }^{88}$ Benign lesions have very little chance of malignant transformation and rarely require resection, but unfortunately they could be difficult to sample to ensure their diagnosis. Given the morbidity associated with

Table 5 Main miRNAs deregulated in pancreatic cystic lesions

\begin{tabular}{|c|c|c|c|}
\hline miRNA & Lesion & Regulation & References \\
\hline \multirow[t]{8}{*}{$\operatorname{miR}-21$} & $\begin{array}{l}\text { Malignant cyst fluid vs benign cyst } \\
\text { fluid }\end{array}$ & Upregulated & 30 \\
\hline & $\begin{array}{l}\text { Invasive IPMN vs non-invasive } \\
\text { IPMN vs normal controls }\end{array}$ & Upregulated & 40 \\
\hline & IPMNs vs benign lesions & Upregulated & 28 \\
\hline & IPMNs vs non-neoplastic pancreas & Upregulated & 43 \\
\hline & IPMN vs PDAC & Downregulated & 46 \\
\hline & IPMN vs PDAC & Downregulated & 49 \\
\hline & $\begin{array}{l}\text { Malignant lesions vs benign lesions } \\
\text { vs normal controls }\end{array}$ & Upregulated & 47 \\
\hline & $\begin{array}{l}\text { Mucinous lesions vs non-mucinous } \\
\text { cyst }\end{array}$ & Upregulated & 29 \\
\hline \multirow[t]{4}{*}{ miR-221 } & $\begin{array}{l}\text { Malignant cyst fluid vs benign cyst } \\
\text { fluid }\end{array}$ & Upregulated & 30 \\
\hline & IPMNs vs non-neoplastic pancreas & Upregulated & 43 \\
\hline & IPMN vs PDAC & Downregulated & 49 \\
\hline & $\begin{array}{l}\text { Mucinous lesions vs non-mucinous } \\
\text { cyst }\end{array}$ & Upregulated & 29 \\
\hline \multirow[t]{4}{*}{ miR-155 } & $\begin{array}{l}\text { Invasive IPMN vs non-invasive } \\
\text { IPMN vs normal controls }\end{array}$ & Upregulated & 40 \\
\hline & IPMNs vs non-neoplastic pancreas & Upregulated & 43 \\
\hline & IPMN vs PDAC & Downregulated & 49 \\
\hline & $\begin{array}{l}\text { Malignant lesions vs benign lesions } \\
\text { vs normal controls }\end{array}$ & Upregulated & 47 \\
\hline miR-210 & IPMNs vs non-neoplastic pancreas & Upregulated & 43 \\
\hline miR-130a & HR-IPMN vs LR-IPMN & Downregulated & 51 \\
\hline
\end{tabular}

pancreatectomy, proper selection of patients for surgery should extend beyond size and morphology criteria, thus using assays for molecular markers as miRNAs (table 5).

Farrell et $a l^{30}$ showed that miR-21 expression progressively increased from its lowest values in benign cyst fluid to its highest values in malignant cyst fluid. Premalignant cyst fluid contained an intermediate amount of miR-21, and its expression was significantly different between benign cyst fluid and premalignant cyst fluid. The authors observed that, other than miR-21, also miR-221 expression was significantly higher in malignant cyst fluid compared with benign or premalignant fluid, even if miR-221 levels were not significantly different between benign and premalignant fluid samples. This evidence led them to conclude that miR-21 and miR-221 may be useful markers of advanced disease. ${ }^{30}$ A possible correlation of miR-21 with the progression from benign lesions to invasive IPMNs was hypothesised also by Caponi and colleagues. In fact, significant differences in miR-21 expression in normal versus non-invasive IPMNs versus invasive IPMNs were observed. ${ }^{40}$ Moreover, strong interaction of miR-21 values and clinical outcome was demonstrated: patients with high miR-21 expression in invasive IPMNs had a significantly shorter median compared with patients with miR-21 expression lower than the median value. ${ }^{40}$ In this study, also miR-155 expression was observed as significantly upregulated between normal, non-invasive and invasive IPMNs. ${ }^{40}$ Ryu and colleagues analysed pancreatic cyst fluid specimens in a series of 40 patients and identified a significantly higher relative fold expression of three miRNAs (miR-21, miR-221 and miR-17-3p) in the mucinous precursor lesions versus the non-mucinous cysts. According to receiver-operating characteristic curves, miR-21 had the best performance criteria, as a median specificity of $76 \%$ at a sensitivity of $80 \%$ in differentiating mucinous versus non-mucinous lesions. ${ }^{29}$

In a paper by Matthaei et $a l^{28}$ the authors identified 26 and 37 candidate miRNAs that distinguish low-grade from highgrade IPMNs using FFPE and cyst fluid specimens, respectively. A subset of 18 miRNAs, selected from FFPE and cyst fluid data, separated high-grade IPMNs from low-grade IPMNs, serous cystadenomas and uncommon cysts, such as solid pseudopapillary neoplasms and cystic PanNETs. As in a previous study, also in this paper miR-21 was upregulated in IPMNs compared with benign lesions (eg, serous cystadenomas). ${ }^{28}$

In a study performed on cryostat embedded sections, miR-21 and miR-155 had the highest relative fold expression levels in IPMNs versus non-neoplastic pancreas ${ }^{43}$ and the authors observed that both miRNAs (miR-21 and miR-155) were frequently upregulated within the neoplastic epithelium of IPMNs. In this study, also other eight miRNAs (miR-107, miR-223, miR-181c, miR-181a, miR-221, miR-210, miR-16 and miR-100) were significantly upregulated in IPMN if compared with non-neoplastic pancreas. ${ }^{43}$

In a paper by Lubezky et $a l,{ }^{47}$ the expression values of miR-21 and miR-155 in disease tissues compared with that of 'healthy' tissues were significantly higher both in benign lesions (eg, low-grade IPMN) and in malignant ones (eg, high-grade IPMN and invasive carcinoma arising in IPMN). Moreover, they observed that expression of these miRNAs was higher in malignant than in benign lesions. ${ }^{47}$

Lee and colleagues tried to investigate whether differences in miRNAs expression were appreciable between non-malignant pancreatic cystic neoplasms and PDAC. They observed that miR-31-5p, miR-483-5p, miR-99a-5p and miR-375 allowed them to distinguish serous cystadenoma from all mucinous cystic lesions (MCN, branch duct-IPMN and main duct-IPMN) 
and PDAC with $90 \%$ sensitivity and $100 \%$ specificity. ${ }^{46} \mathrm{MCN}$ were accurately differentiated (sensitivity and specificity of $100 \%$ and $100 \%$, respectively) from serous cystadenoma, IPMN and PDAC if miR-10b-5p, miR-202-3p, miR-210 and miR-375 were analysed. In this study, two panels were set-up to distinguish MCN from BD-IPMN (miR-192-5p, miR-202-3p, miR-337-5p and miR-130-3p) and to distinguish PDAC from IPMN (miR-21-5p, miR-485-3p, miR-708-5p and miR-375). ${ }^{46}$

In a study by Permuth and colleagues, 13 of 35 investigated miRNAs (miR-100, miR-99b, miR-99a, miR-342-3p, miR-126, miR-888, miR-130a, let-7c, miR-150, miR-296, miR-199a, miR-199a-3p and miR-302a) were significantly deregulated between high-risk IPMN (HR-IPMN) and low-risk IPMN (LR-IPMN). ${ }^{51}$ In particular, six miRNAs (miR-100, miR-99b, miR-99a, miR-342-3p, miR-126 and miR-130a) were downregulated in most HR-IPMNs versus LR-IPMNs, suggesting that low or reduced levels of these miRNAs (and possibly increased levels of target genes they regulate) may be associated with progression to invasion. Among these six miRNAs, downregulation of miR-130a was most strongly associated with HR-IPMN status. $^{51}$

\section{MIRNA IN EARLY DETECTION OF PANCREATIC LESIONS}

Distinguishing between pancreatic adenocarcinoma and nonneoplastic pancreatic diseases (eg, CP) may be very difficult using only imaging technique. For this reason, it is of fundamental importance to identify accurate markers for early detection of PC. CA19-9 is widely adopted, but its use is limited to monitoring responses to therapy, not as a diagnostic marker, because false-positive results are common among patients with benign pancreatic biliary disorders. ${ }^{1}{ }^{89}$ Improved circulating markers of pancreatic lesions could facilitate the early detection of PC and miRNAs could represent promising candidates (table 6).

As described in the section 'Pancreatic ductal adenocarcinoma', upregulation of miR-21 $\begin{array}{llllllll}13 & 23 & 26 & 28-30 & 39 & 40 & 49 & 50\end{array}$ and

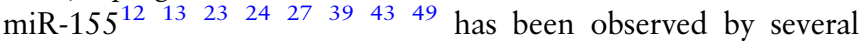
studies in PDAC tissues and in IPMN if compared with nonneoplastic controls. However, miR-21 upregulation is not a specific marker of pancreatic disease; in fact, miR-21 upregulation has been observed also in patients with gastric carcinoma, ${ }^{90}$ hepatocellular carcinoma ${ }^{91}$ or prostate cancer. ${ }^{92}$

In a study by Ali et al performed on plasma of 76 patients, the expression levels of miR-21 were increased to more than 10 folds in patients with PC if compared to miRNA levels from controls, while the values of tumour suppressor miRNAs (eg, let-7 family or miR-146a) were significantly reduced in most PC samples. According to the authors, higher expression of miR-21 could be used as a prognostic biomarker for worse survival of patients with PC. ${ }^{69}$

MiR-21 and miR-155 were observed upregulated (miR-21: 2-fold to 20-fold; miR-155: 2-fold to 40-fold) in plasma of cancer samples in a study investigating 49 cancer samples and 36 control specimens. ${ }^{77}$ The combined analysis of miR-21 and miR-155 with other two miRNAs (miR-210 and miR-196) could help in discriminating patients with PDAC from normal healthy individuals (sensitivity and specificity of $64 \%$ and $89 \%$, respectively). ${ }^{77}$ As reported in the section 'miRNA deregulated in solid lesions', miR-21, miR-155 and miR-196a were found to be upregulated in pancreatic lesions also in a study by Kong et $a l^{78}$ and according to them, the upregulation of miR-21 could differentiate PDAC from CP and healthy individuals.
Table 6 Circulating miRNA in patients with pancreatic lesions

\begin{tabular}{|c|c|c|c|c|}
\hline miRNA & Material & Lesions vs controls & $\begin{array}{l}\text { miRNA } \\
\text { status }\end{array}$ & References \\
\hline \multirow[t]{4}{*}{ miR-21 } & Plasma & $\begin{array}{l}\text { PC vs healthy } \\
\text { subjects }\end{array}$ & Upregulated & 69 \\
\hline & Plasma & $\begin{array}{l}\text { PC vs healthy } \\
\text { subjects }\end{array}$ & Upregulated & 77 \\
\hline & Serum & $\begin{array}{l}\text { PDAC vs CP vs } \\
\text { healthy subjects }\end{array}$ & Upregulated & 78 \\
\hline & Serum & $\begin{array}{l}\text { PC vs healthy } \\
\text { subjects }\end{array}$ & Upregulated & 74 \\
\hline \multirow[t]{2}{*}{ miR-221 } & Plasma & $\begin{array}{l}\text { PC vs benign lesions } \\
\text { vs healthy controls }\end{array}$ & Upregulated & 71 \\
\hline & Serum & PC vs CRC & Upregulated & 79 \\
\hline \multirow[t]{5}{*}{ miR-155 } & Plasma & $\begin{array}{l}\text { PC vs healthy } \\
\text { subjects }\end{array}$ & Upregulated & 77 \\
\hline & Plasma & $P C$ vs $C P$ & Upregulated & 79 \\
\hline & Serum & $\begin{array}{l}\text { PDAC and CP vs } \\
\text { healthy subjects }\end{array}$ & Upregulated & 78 \\
\hline & $\begin{array}{l}\text { Pancreatic } \\
\text { juice, bile, } \\
\text { plasma }\end{array}$ & PDAC vs CP & Upregulated & 61 \\
\hline & $\begin{array}{l}\text { Pancreatic } \\
\text { juice }\end{array}$ & $\begin{array}{l}\text { PC vs CP vs healthy } \\
\text { subjects }\end{array}$ & Upregulated & 53 \\
\hline \multirow[t]{3}{*}{$\operatorname{miR}-210$} & Plasma & $\begin{array}{l}\text { PC vs healthy } \\
\text { subjects }\end{array}$ & Upregulated & 77 \\
\hline & Plasma & $\begin{array}{l}\text { PC vs healthy } \\
\text { subjects }\end{array}$ & Upregulated & 70 \\
\hline & & $\begin{array}{l}\text { PDAC vs } \\
\text { non-pancreatic } \\
\text { non-healthy controls }\end{array}$ & Upregulated & 62 \\
\hline \multirow[t]{3}{*}{ miR-196 } & Plasma & $\begin{array}{l}\text { PC vs healthy } \\
\text { subjects }\end{array}$ & Upregulated & 77 \\
\hline & Plasma & $P C$ vs $C P$ & Upregulated & 73 \\
\hline & Serum & $\begin{array}{l}\text { PDAC and CP vs } \\
\text { healthy subjects }\end{array}$ & Upregulated & 78 \\
\hline \multirow[t]{2}{*}{ miR-10 } & Serum & $\begin{array}{l}\text { PC vs healthy } \\
\text { subjects }\end{array}$ & Upregulated & 79 \\
\hline & Plasma & $\begin{array}{l}\text { PDAC vs control } \\
\text { normal subjects }\end{array}$ & Upregulated & 94 \\
\hline
\end{tabular}

Only miRNA observed deregulated in at least two papers have been reported. $\mathrm{CP}$, chronic pancreatitis; CRC, colorectal carcinoma; PC, pancreatic cancer; PDAC, pancreatic ductal adenocarcinoma.

Nevertheless, miR-21 has been detected deregulated in several papers, and ${ }^{69} 7893$ one study performed in plasma, pancreatic juice and bile aspirates for 10 miRNAs (miR-10b, miR-21, miR-30c, miR-106b, miR-132, miR-155, miR-181a, miR-181b, miR-196a and miR-212) revealed that miR-21 is not deregulated in PDAC towards CP and health controls. For this reason, the authors assert that, nevertheless, miR-21 is important in PDAC, and it did not serve as a good plasma, bile or pancreatic juice biomarker. ${ }^{61}$ Interestingly, in this paper, miR-155 had an excellent accuracy in distinguishing PDAC from CP subjects. ${ }^{61}$ Another paper has not observed upregulation of miR-21 in patients with PC: $:^{53}$ in the analysis performed on 138 patients with PC, 107 patients with $\mathrm{CP}$ and 68 normal controls, the expression levels of miR-21 were not significantly different in patients with PC if compared with CP and normal groups. ${ }^{53}$ Intriguingly also in this case, as in the study by Cote and colleagues, miR-155 was upregulated in patients with PC. ${ }^{53}$ On the contrary, the analysis of pancreatic juice samples obtained from patients with PDAC revealed that expression levels of both miR-21 and miR-155 were significantly higher in patients with PDAC as compared to CP and normal pancreas. ${ }^{53}$ Using gold nanoprism-based plasmonic biosensor, Joshi and colleagues observed that miR-21 concentration in extracted samples was at 
least twofold lower than in the pure plasma samples. According to the authors, this is due to loss of miRNAs during the RNA extraction process, which requires multiple steps for RNA purification. Therefore, according to them, the most widely used qRT-PCR method to determine the concentration of miRNAs in patients may not accurately represent the actual concentration of miRNAs in analysed specimens. ${ }^{94}$

As described in tables 2-4, miR-21 and miR-155 were not the only miRNAs to be upregulated in PDAC specimens. MiR-210 is another miRNA frequently found upregulated in $\mathrm{PDAC}^{12} 50$ or in IPMN. ${ }^{43}$ Circulating miR-210 was found to be significantly elevated in patients with PC if compared with normal controls and may serve as a reliable blood-based biomarker. ${ }^{70}$ No direct correlation between circulating miR-210 levels and CA19-9 was feasible to determine the statistical contribution of miR-210 in addition to CA19-9 for the detection of malignancy of the lesions. ${ }^{70}$ High level of miR-210 (elevated by 2-fold to-28 fold) has been observed in plasma of patients with PC in the study by Wang and colleagues. ${ }^{77}$ In 2014 , it was observed that the combination of CA19-9 with 4 miRNAs upregulated in PDAC (miR-205, miR-210, miR-492 and miR-1247) had a sensitivity of $91 \%$ and a specificity of $100 \%$ in distinguishing PC samples from control subjects. ${ }^{62}$ Elevated levels of all four miRNAs were associated with shorter OS. Moreover, subjects with low levels of both miR-205 and miR-210 appeared less likely to have lymph node metastasis than patients with high levels of both miRNAs. ${ }^{62}$

MiR-221 has been identified as regulators of epithelial-to-mesenchymal transition. ${ }^{95}$ MiR-221 has been upregulated in several cancers as breast carcinomas, ${ }^{96}$ thyroid tumours, ${ }^{97}$ glioblastoma ${ }^{98}$ and also frequently in PDAC (tables 2-4). ${ }^{12} 1320232427394950$ MiR-221 upregulation in plasma has been associated with melanoma, ${ }^{99}$ hepatocellular carcinoma ${ }^{100}$ and colorectal cancer (CRC). ${ }^{101}$ Kawaguchi et al evaluated miR-221 and miR-375 expression in plasma of 47 pancreatic patients compared with 30 healthy volunteers. The plasma concentration of miR-221 in patients with PC was significantly higher than in normal subjects. On the contrary, plasma concentrations of miR-375 were lower in patients with PC than in controls. ${ }^{71}$ MiR-221 concentrations in patients with PC was significantly higher also if compared with levels in subjects with pancreatic benign lesions (eg, IPMN, serous cystadenoma and pancreatitis). Otherwise, no differences were observed between miR-221 levels in pancreatic benign lesions and those in healthy volunteers. ${ }^{71}$ Moreover, the authors found plasma miR-221 concentrations to be significantly reduced in postoperative samples if compared with paired preoperative (almost 1 month after surgery) plasma samples patients with PC who underwent curative pancreatectomy, suggesting that expression levels of plasma miR-221 may reflect tumour dynamics in subjects with PC. ${ }^{71}$

As observed for miR-21, some studies do not report upregulation of miR-221 in plasma of subjects with PC. In fact, miR-221 was not observed deregulated in plasma of patients with PC if compared with levels in healthy subjects in a study by LaConti. ${ }^{79}$ However, in this study the authors observed that miR-221 was upregulated in plasma of patients with PC compared with levels observed in plasma of patients with CRC. ${ }^{79}$

Several other miRNAs were observed deregulated in plasma of patients with PC compared with normal control subjects. In the aforementioned paper by LaConti, miR-100a and miR-10 were significantly increased in patients with PC compared with non-cancer controls. ${ }^{79}$ MiR-10b levels were observed higher in patients with PDAC in plasma from six patients towards six normal control subjects using gold nanoprism-based plasmonic biosensor. $^{94} \mathrm{Li}$ and colleagues measured miR-200a and miR-200b concentrations in 45 patients with PC and 32 healthy controls. ${ }^{80}$ Both miRNAs were significantly elevated in sera of patients with PC compared with healthy controls. No significant differences were observed in expression levels of miR-200a and miR-200b in the serum of patients with PC if compared with that of patients with $\mathrm{CP}^{80}$

Concentration of miR-18a was significantly higher in the plasma from patients with cancer compared with that in normal volunteers. ${ }^{76}$ Moreover, the concentration of miR-18a was found to be significantly reduced in the postoperative samples if analysed in paired preoperative and postoperative plasma samples obtained from patients with PC who underwent curative pancreatectomy. ${ }^{76}$

According to Liu et al, ${ }^{73}$ only miR-16 and miR-196a have an independent role in discriminating PC from normal and CP in plasma of 138 and 107 patients, respectively. After including serum CA19-9 in the logistic model, the combination of miR-16, miR-196a and CA19-9 was more effective for discriminating $\mathrm{PC}$ from non-PC and for discriminating PC from $\mathrm{CP}^{73}$ Moreover, according to a study by Kong and colleagues, serum miR-196a expression level in the unresectable PDAC (stages III and IV) was significantly higher than that in the resectable group (stages I and II), indicating that miR-196a could be a useful biomarker for differentiating resectable from unresectable PDAC. High expression of miR-196a has been also correlated with a worse prognosis. ${ }^{78}$

In a cohort of 292 circulating PBMC samples, Wang and colleagues found miR-27a-3p, miR-16-5p and miR-15-5p to be upregulated in patients with PC. Furthermore, according to this study, miR-27a-3p could discriminate patients with PC from healthy controls and, together with CA19-9, allows us to distinguish PC from benign pancreatic disease. ${ }^{68}$

Identifying a single miRNA (or few miRNAs) able to distinguish between malignant (PC) and benign disease or normal subject could be a big issue. For this reason, identifying a panel of circulating altered miRNAs could be very useful in the analysis of malignant pancreatic lesion.

In the aforementioned study by Ali et al, ${ }^{69}$ performed on plasma of 76 patients, miRNA expression profiling revealed 91 miRNAs differentially expressed (54 upregulated and 37 downregulated) between patients with PC and those chosen as controls. Cote et al found that five miRNAs (miR-10b, miR-30c, miR-106b, miR-155 and miR-212) in plasma and bile provided very good accuracy (area under the curve >0.90) for distinguishing patients with PDAC from controls. In addition, each miRNA had good accuracy in distinguishing PDAC from subjects with CP. In bile, all these miRNAs had a sensitivity of $96 \%$ and a specificity from $98 \%$ to $100 \%$. In plasma, the sensitivity ranged from $73 \%$ (miR-30c) to $100 \%$ (miR-106b) and specificity from $83 \%$ (miR-212) to $100 \%$ (miR-10b and miR-155). ${ }^{61}$

A genome-wide miRNAs expression profiling of serum showed that patients with PC had 44 upregulated miRNAs and 19 downregulated miRNAs compared with controls. ${ }^{74}$ The qRT-PCR validation assay allowed us to identify a panel of seven miRNAs (miR-20a, miR-21, miR-24, miR-25, miR-99a, miR-185 and miR-191) that were significantly altered in patients with PC compared with control samples. ${ }^{74}$

In a complete miRNA signature of 116 blood samples (45 from patients with PDAC, 38 from $\mathrm{CP}$ and 33 from healthy individuals), 87 miRNAs differentiated between patients with ductal adenocarcinoma and healthy individuals, and 18 miRNAs were different between CP and healthy individuals. ${ }^{21}$ 
However, there was not a single miRNA in blood that allowed us to distinguish between the two diseases even if there were 100 miRNAs found in the tissue samples that permitted a separation of patients with PDAC from those with chronic. ${ }^{21}$

A multivariable analysis in 435 cases suspected for PC with 312 healthy participants demonstrated that 38 miRNAs had the potential to separate patients with PC from healthy participants and patients with CP. This study identified two miRNA panels in whole blood that had the ability to distinguish, to a certain degree, patients with PC from healthy younger controls. ${ }^{54}$

\section{CONCLUSIONS}

Identifying patients with malignant pancreatic mass could be very useful in the management of patients with pancreatic lesions. The identification of circulating markers represents a non-invasive approach and miRNAs are very promising biological markers. However, it is clear that a panel of miRNAs need to be used for having high sensitive and specific results: in fact, miRNAs may show the same deregulation pattern in differ-

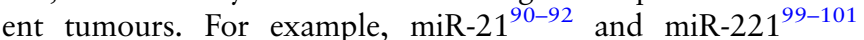
upregulation observed in plasma of subject with PCs has been also observed in patients with gastric carcinoma, hepatocellular carcinoma, prostate cancer, melanoma, hepatocellular carcinoma or CRC. Even if it is possible to hypothesise a miRNA panel distinguishing PDAC from normal pancreas (eg, the one by $\mathrm{Ma}$ et $a l^{84}$ or the one reported in the present paper), it should be considered that the more clinical relevant issues is to differentiate PDAC, or early malignant lesions, not only from normal pancreas but also from benign lesions, as previously highlighted by Frampton et al. ${ }^{85}$ Moreover, one miRNA may show a different level of expression according to studies and specifically two main factors could influence the results: (i) selection of the method and (ii) selection of control groups. According to the authors, the standardisation of these two variables and a high sensitive and specific panel of miRNAs able to distinguish PDAC (or early malignant lesions) not only from normal pancreas but also from benign lesions are fundamental prerequisites before using analysis of miRNAs in clinical practice as molecular markers of PCs or as markers for early detection of pancreatic lesions.

\section{Take home messages}

- MicroRNAs (MiRNAs) are very promising biological markers for pancreatic cancer.

- MiRNAs may show a different level of expression according to method and control group.

- Standardisation of experimental variables is crucial in miRNA analysis.

- A panel of miRNAs needs to be used for having high sensitive and specific results.

- A standardised panel of sensitive and specific miRNAs should be enforced.

\section{Handling editor Runjan Chetty}

Contributors MV and GA contributed equally to this work. DdB conceptualised the paper. DdB, MV and GA conducted the literature search. All authors were involved in the manuscript development, in its revision and in the final approval of the version.

Competing interests None declared.

Provenance and peer review Not commissioned; externally peer reviewed.

\section{REFERENCES}

1 Goggins M. Identifying molecular markers for the early detection of pancreatic neoplasia. Semin Oncol 2007;34:303-10.

2 Khalid A, Finkelstein S, McGrath K. Molecular diagnosis of solid and cystic lesions of the pancreas. Clin Lab Med 2005;25:101-16.

3 Cooper CL, O'Toole SA, Kench JG. Classification, morphology and molecular pathology of premalignant lesions of the pancreas. Pathology 2013;45:286-304

4 Distler M, Aust D, Weitz J, et al. Precursor lesions for sporadic pancreatic cancer: PanIN, IPMN, and MCN. BioMed research international 2014;2014:474905.

5 Hong SM, Park JY, Hruban RH, et al. Molecular signatures of pancreatic cancer. Arch Pathol Lab Med 2011;135:716-27.

6 Galasso M, Sandhu SK, Volinia S. MicroRNA expression signatures in solid malignancies. Cancer J 2012;18:238-43.

7 Lynam-Lennon N, Maher SG, Reynolds JV. The roles of microRNA in cancer and apoptosis. Biol Rev Camb Philos Soc 2009;84:55-71.

8 Nana-Sinkam SP, Croce CM. Clinical applications for microRNAs in cancer. Clin Pharmacol Ther 2013;93:98-104.

9 Zhang B, Pan X, Cobb GP, et al. microRNAs as oncogenes and tumor suppressors Dev Biol 2007:302:1-12.

10 Srivastava SK, Arora S, Singh S, et al. MicroRNAs in pancreatic malignancy: progress and promises. Cancer Lett 2014;347:167-74.

11 Greenblatt DY, Kelly KJ, Rajamanickam V, et al. Preoperative factors predict perioperative morbidity and mortality after pancreaticoduodenectomy. Ann Surg Oncol 2011;18:2126-35

12 Greither T, Grochola LF, Udelnow A, et al. Elevated expression of microRNAs 155, 203, 210 and 222 in pancreatic tumors is associated with poorer survival. Int J Cancer 2010;126:73-80.

13 Lee EJ, Gusev Y, Jiang J, et al. Expression profiling identifies microRNA signature in pancreatic cancer. Int J Cancer 2007;120:1046-54.

14 Li SC, Essaghir A, Martijn C, et al. Global microRNA profiling of well-differentiated small intestinal neuroendocrine tumors. Mod Pathol 2013;26:685-96.

15 Park JK, Henry JC, Jiang J, et al. miR-132 and miR-212 are increased in pancreatic cancer and target the retinoblastoma tumor suppressor. Biochem Biophys Res Commun 2011:406:518-23.

16 Park M, Kim M, Hwang D, et al. Characterization of gene expression and activated signaling pathways in solid-pseudopapillary neoplasm of pancreas. Mod Pathol 2014;27:580-93.

17 Roldo C, Missiaglia E, Hagan JP, et al. MicroRNA expression abnormalities in pancreatic endocrine and acinar tumors are associated with distinctive pathologic features and clinical behavior. J Clin Oncol 2006;24:4677-84.

18 Xiao J, Peng F, Yu C, et al. microRNA-137 modulates pancreatic cancer cells tumor growth, invasion and sensitivity to chemotherapy. Int I Clin Exp Pathol 2014;7:7442-50.

19 Yang JY, Sun YW, Liu DJ, et al. MicroRNAs in stool samples as potential screening biomarkers for pancreatic ductal adenocarcinoma cancer. Am J Cancer Res 2014;4:663-73

20 Zhang $Y$, Li M, Wang $\mathrm{H}$, et al. Profiling of 95 microRNAs in pancreatic cancer cell lines and surgical specimens by real-time PCR analysis. World J Surg 2009;33:698-709.

21 Bauer AS, Keller A, Costello E, et al. Diagnosis of pancreatic ducta adenocarcinoma and chronic pancreatitis by measurement of microRNA abundance in blood and tissue. PLoS One 2012;7:e34151.

22 Szafranska AE, Davison TS, John J, et al. MicroRNA expression alterations are linked to tumorigenesis and non-neoplastic processes in pancreatic ductal adenocarcinoma. Oncogene 2007;26:4442-52.

23 Jamieson NB, Morran DC, Morton JP, et al. MicroRNA molecular profiles associated with diagnosis, clinicopathologic criteria, and overall survival in patients with resectable pancreatic ductal adenocarcinoma. Clin Cancer Res 2012:18:534-45.

24 Piepoli A, Tavano F, Copetti M, et al. Mirna expression profiles identify drivers in colorectal and pancreatic cancers. PLoS One 2012;7:e33663.

25 Eloubeidi MA, Chen VK, Eltoum IA, et al. Endoscopic ultrasound-guided fine needle aspiration biopsy of patients with suspected pancreatic cancer: diagnostic accuracy and acute and 30-day complications. Am J Gastroenterol 2003;98:2663-8.

26 Hong TH, Park IY. MicroRNA expression profiling of diagnostic needle aspirates from surgical pancreatic cancer specimens. Ann Surg Treat Res 2014;87:290-7.

27 Szafranska AE, Doleshal M, Edmunds HS, et al. Analysis of microRNAs in pancreatic fine-needle aspirates can classify benign and malignant tissues. Clin Chem 2008;54:1716-24.

28 Matthaei $\mathrm{H}$, Wylie $\mathrm{D}$, Lloyd MB, et al. miRNA biomarkers in cyst fluid augment the diagnosis and management of pancreatic cysts. Clin Cancer Res 2012;18:4713-24.

29 Ryu JK, Matthaei H, Dal Molin M, et al. Elevated microRNA miR-21 levels in pancreatic cyst fluid are predictive of mucinous precursor lesions of ductal adenocarcinoma. Pancreatology 2011;11:343-50.

30 Farrell JJ, Toste $\mathrm{P}, \mathrm{Wu} \mathrm{N}$, et al. Endoscopically acquired pancreatic cyst fluid microRNA 21 and 221 are associated with invasive cancer. Am J Gastroenterol 2013;108:1352-9. 
31 Henry JC, Bassi C, Giovinazzo F, et al. MicroRNA from pancreatic duct aspirate differentiates cystic lesions of the pancreas. Ann Surg Oncol 2013;20(Suppl 3): S661-666.

32 Xi Y, Nakajima G, Gavin E, et al. Systematic analysis of microRNA expression of RNA extracted from fresh frozen and formalin-fixed paraffin-embedded samples. RNA 2007:13:1668-74.

33 Weng $\mathrm{L}, \mathrm{Wu}$ X, Gao H, et al. MicroRNA profiling of clear cell renal cell carcinoma by whole-genome small RNA deep sequencing of paired frozen and formalin-fixed, paraffin-embedded tissue specimens. J Pathol 2010;222:41-51.

34 Nonn L, Vaishnav A, Gallagher L, et al. mRNA and micro-RNA expression analysis in laser-capture microdissected prostate biopsies: valuable tool for risk assessment and prevention trials. Exp Mol Pathol 2010;88:45-51.

35 Leite KR, Canavez JM, Reis ST, et al. miRNA analysis of prostate cancer by quantitative real time PCR: comparison between formalin-fixed paraffin embedded and fresh-frozen tissue. Urol Oncol 2011;29:533-7.

36 Hui $A B$, Shi W, Boutros PC, et al. Robust global micro-RNA profiling with formalin-fixed paraffin-embedded breast cancer tissues. Lab Invest 2009;89:597-606

37 de Biase D, Visani M, Morandi L, et al. miRNAs expression analysis in paired fresh/frozen and dissected formalin fixed and paraffin embedded glioblastoma using real-time pCR. PLoS One 2012;7:e35596.

38 Ali S, Saleh $\mathrm{H}$, Sethi $\mathrm{S}$, et al. MicroRNA profiling of diagnostic needle aspirates from patients with pancreatic cancer. Br J Cancer 2012;107:1354-60.

39 Bloomston M, Frankel WL, Petrocca F, et al. MicroRNA expression patterns to differentiate pancreatic adenocarcinoma from normal pancreas and chronic pancreatitis. JAMA 2007;297:1901-8.

40 Caponi S, Funel N, Frampton AE, et al. The good, the bad and the ugly: a tale of miR-101, miR-21 and miR-155 in pancreatic intraductal papillary mucinous neoplasms. Ann Oncol 2013;24:734-41.

41 du Rieu MC, Torrisani J, Selves J, et al. MicroRNA-21 is induced early in pancreatic ductal adenocarcinoma precursor lesions. Clin Chem 2010;56:603-12.

42 Giovannetti $E$, van der Velde $A$, Funel N, et al. High-throughput microRNA (miRNAs) arrays unravel the prognostic role of MiR-211 in pancreatic cancer. PLoS One 2012;7:e49145.

43 Habbe N, Koorstra JB, Mendell JT, et al. MicroRNA miR-155 is a biomarker of early pancreatic neoplasia. Cancer Biol Ther 2009;8:340-6.

44 Hanoun N, Delpu Y, Suriawinata AA, et al. The silencing of microRNA 148a production by DNA hypermethylation is an early event in pancreatic carcinogenesis. Clin Chem 2010;56:1107-18.

45 Jiao LR, Frampton $A E$, Jacob J, et al. MicroRNAs targeting oncogenes are down-regulated in pancreatic malignant transformation from benign tumors. PLOS One 2012;7:e32068

46 Lee LS, Szafranska-Schwarzbach AE, Wylie D, et al. Investigating microRNA expression profiles in pancreatic cystic neoplasms. Clin Trans/ Gastroenterol 2014;5:e47.

47 Lubezky N, Loewenstein S, Ben-Haim M, et al. MicroRNA expression signatures in intraductal papillary mucinous neoplasm of the pancreas. Surgery 2013;153:663-72.

48 Munding JB, Adai AT, Maghnouj A, et al. Global microRNA expression profiling of microdissected tissues identifies miR-135b as a novel biomarker for pancreatic ductal adenocarcinoma. Int J Cancer 2012;131:E86-95.

49 Panarelli NC, Chen YT, Zhou XK, et al. MicroRNA expression aids the preoperative diagnosis of pancreatic ductal adenocarcinoma. Pancreas 2012;41:685-90.

50 Papaconstantinou IG, Manta A, Gazouli M, et al. Expression of microRNAs in patients with pancreatic cancer and its prognostic significance. Pancreas 2013;42:67-71.

51 Permuth-Wey J, Chen YA, Fisher K, et al. A genome-wide investigation of microRNA expression identifies biologically-meaningful microRNAs that distinguish between high-risk and low-risk intraductal papillary mucinous neoplasms of the pancreas. PLoS One 2015;10:e0116869.

52 Preis M, Gardner TB, Gordon SR, et al. MicroRNA-10b expression correlates with response to neoadjuvant therapy and survival in pancreatic ductal adenocarcinoma. Clin Cancer Res 2011;17:5812-21.

53 Sadakari Y, Ohtsuka T, Ohuchida K, et al. MicroRNA expression analyses in preoperative pancreatic juice samples of pancreatic ductal adenocarcinoma. JOP 2010;11:587-92.

54 Schultz NA, Werner J, Willenbrock $H$, et al. MicroRNA expression profiles associated with pancreatic adenocarcinoma and ampullary adenocarcinoma. Mod Pathol 2012;25:1609-22.

55 Xue Y, Abou Tayoun AN, Abo KM, et al. MicroRNAs as diagnostic markers for pancreatic ductal adenocarcinoma and its precursor, pancreatic intraepithelial neoplasm. Cancer Genet 2013;206:217-21.

56 Yu J, Ohuchida K, Mizumoto K, et al. MicroRNA, hsa-miR-200c, is an independent prognostic factor in pancreatic cancer and its upregulation inhibits pancreatic cancer invasion but increases cell proliferation. Mol Cancer 2010;9:169.

57 Dillhoff $M$, Liu J, Frankel W, et al. MicroRNA-21 is overexpressed in pancreatic cancer and a potential predictor of survival. J Gastrointest Surg 2008;12:2171-6.
58 Nakata K, Ohuchida K, Mizumoto K, et al. MicroRNA-10b is overexpressed in pancreatic cancer, promotes its invasiveness, and correlates with a poor prognosis. Surgery 2011;150:916-22.

59 Fujita N, Noda Y, Kobayashi G, et al. Endoscopic approach to early diagnosis of pancreatic cancer. Pancreas 2004;28:279-81.

60 Wakatsuki T, Irisawa A, Bhutani MS, et al. Comparative study of diagnostic value of cytologic sampling by endoscopic ultrasonography-guided fine-needle aspiration and that by endoscopic retrograde pancreatography for the management of pancreatic mass without biliary stricture. J Gastroenterol Hepatol 2005;20:1707-11.

61 Cote GA, Gore AJ, McElyea SD, et al. A pilot study to develop a diagnostic test for pancreatic ductal adenocarcinoma based on differential expression of select miRNA in plasma and bile. Am J Gastroenterol 2014;109:1942-52.

62 Wang J, Raimondo M, Guha S, et al. Circulating microRNAs in pancreatic juice as candidate biomarkers of pancreatic cancer. J Cancer 2014;5:696-705.

63 Le Large TY, Frampton AE, Meijer LL, et al. Usefulness of measuring microRNAs in bile and plasma for pancreatic ductal adenocarcinoma diagnosis. Am J Gastroenterol 2015;110:768-9.

64 Arroyo JD, Chevillet JR, Kroh EM, et al. Argonaute 2 complexes carry a population of circulating microRNAs independent of vesicles in human plasma. Proc Natl Acad Sci USA 2011;108:5003-8.

65 Mitchell PS, Parkin RK, Kroh EM, et al. Circulating microRNAs as stable blood-based markers for cancer detection. Proc Natl Acad Sci USA 2008;105:10513-18.

66 Schultz NA, Dehlendorff C, Jensen BV, et al. MicroRNA biomarkers in whole blood for detection of pancreatic cancer. JAMA 2014;311:392-404.

67 Baine MJ, Mallya K, Batra SK. Quantitative real-time PCR expression analysis of peripheral blood mononuclear cells in pancreatic cancer patients. Methods $\mathrm{Mol}$ Biol 2013;980:157-73.

68 Wang WS, Liu LX, Li GP, et al. Combined serum CA19-9 and miR-27a-3p in peripheral blood mononuclear cells to diagnose pancreatic cancer. Cancer Prev Res (Phila) 2013;6:331-8.

69 Ali S, Almhanna K, Chen W, et al. Differentially expressed miRNAs in the plasma may provide a molecular signature for aggressive pancreatic cancer. Am J Transl Res 2010;3:28-47

70 Ho AS, Huang $X, C_{1}$, et al. Circulating miR-210 as a novel hypoxia marker in pancreatic cancer. Transl Oncol 2010;3:109-13.

71 Kawaguchi T, Komatsu S, Ichikawa D, et al. Clinical impact of circulating miR-221 in plasma of patients with pancreatic cancer. Br J Cancer 2013;108:361-9.

72 Li A, Yu J, Kim H, et al. Serum miR-1290 as a marker of pancreatic cancer--response. Clin Cancer Res 2013;19:5252-3.

73 Liu J, Gao J, Du Y, et al. Combination of plasma microRNAs with serum CA19-9 for early detection of pancreatic cancer. Int J Cancer 2012;131:683-91.

74 Liu $R$, Chen $X$, Du Y, et al. Serum microRNA expression profile as a biomarker in the diagnosis and prognosis of pancreatic cancer. Clin Chem 2012;58:610-18.

75 Madhavan B, Yue S, Galli U, et al. Combined evaluation of a panel of protein and miRNA serum-exosome biomarkers for pancreatic cancer diagnosis increases sensitivity and specificity. Int J Cancer 2015;136:2616-27.

76 Morimura R, Komatsu S, Ichikawa D, et al. Novel diagnostic value of circulating miR-18a in plasma of patients with pancreatic cancer. $\mathrm{Br} J$ Cancer 2011;105:1733-40.

77 Wang J, Chen J, Chang P, et al. MicroRNAs in plasma of pancreatic ductal adenocarcinoma patients as novel blood-based biomarkers of disease. Cancer Prev Res (Phila) 2009;2:807-13.

78 Kong X, Du Y, Wang G, et al. Detection of differentially expressed microRNAs in serum of pancreatic ductal adenocarcinoma patients: miR-196a could be a potential marker for poor prognosis. Dig Dis Sci 2011;56:602-9.

79 LaConti JJ, Shivapurkar N, Preet A, et al. Tissue and serum microRNAs in the Kras (G12D) transgenic animal model and in patients with pancreatic cancer. PLoS One 2011;6:e20687.

80 Li A, Omura N, Hong $S$, et al. Epigenetic silencing of transcription factor SIP1 in pancreatic cancer cells is associated with elevated expression and blood serum levels of microRNAs miR-200a,b. Cancer Res 2010;70:5226-37.

81 Rosero S, Bravo-Egana V, Jiang Z, et al. MicroRNA signature of the human developing pancreas. BMC Genomics 2010;11:509.

82 Hidalgo M. Pancreatic cancer. N Engl J Med 2010;362:1605-17.

83 Kloppel G, Adsay NV. Chronic pancreatitis and the differential diagnosis versus pancreatic cancer. Arch Pathol Lab Med 2009;133:382-7.

84 Ma MZ, Kong X, Weng MZ, et al. Candidate microRNA biomarkers of pancreatic ductal adenocarcinoma: meta-analysis, experimental validation and clinical significance. J Exp Clin Cancer Res 2013;32:71.

85 Frampton $A E$, Giovannetti $E$, Jamieson NB, et al. A microRNA meta-signature for pancreatic ductal adenocarcinoma. Expert Rev Mol Diagn 2014;14:267-71.

86 Frampton $A E$, Krell J, Jamieson NB, et al. microRNAs with prognostic significance in pancreatic ductal adenocarcinoma: A meta-analysis. Eur J Cancer 2015:51:1389-404.

87 Bosman FT, World Health Organization, International Agency for Research on Cancer. WHO classification of tumours of the digestive system, 4th edn. Lyon: International Agency for Research on Cancer, 2010. 
88 Basturk O, Coban I, Adsay NV. Pancreatic cysts: pathologic classification, differential diagnosis, and clinical implications. Arch Pathol Lab Med 2009; 133:423-38.

89 Steinberg W. The clinical utility of the CA 19-9 tumor-associated antigen. Am J Gastroenterol 1990;85:350-5.

90 Komatsu S, Ichikawa D, Tsujiura M, et al. Prognostic impact of circulating miR-21 in the plasma of patients with gastric carcinoma. Anticancer Res 2013;33:271-6.

$91 \mathrm{Xu} J$, Wu C, Che X, et al. Circulating microRNAs, miR-21, miR-122, and miR-223, in patients with hepatocellular carcinoma or chronic hepatitis. Mol Carcinog 2011;50:136-42.

92 Yaman Agaoglu F, Kovancilar M, Dizdar Y, et al. Investigation of miR-21, miR-141, and miR-221 in blood circulation of patients with prostate cancer. Tumour Biol 2011;32:583-8.

93 Wang J, Yi $X$, Tang $H$, et al. Direct quantification of microRNA at low picomolar level in sera of glioma patients using a competitive hybridization followed by amplified voltammetric detection. Anal Chem 2012;84:6400-6.

94 Joshi GK, Deitz-McElyea S, Johnson M, et al. Highly specific plasmonic biosensors for ultrasensitive microRNA detection in plasma from pancreatic cancer patients. Nano Lett 2014;14:6955-63.
95 Stinson S, Lackner MR, Adai AT, et al. TRPS1 targeting by miR-221/222 promotes the epithelial-to-mesenchymal transition in breast cancer. Science signaling 2011;4:ra41.

96 Zhao JJ, Lin J, Yang H, et al. MicroRNA-221/222 negatively regulates estrogen receptor alpha and is associated with tamoxifen resistance in breast cancer. J Biol Chem 2008;283:31079-86.

97 Visone R, Russo L, Pallante P, et al. MicroRnAs (miR)-221 and miR-222, both overexpressed in human thyroid papillary carcinomas, regulate $\mathrm{p} 27 \mathrm{Kip} 1$ protein levels and cell cycle. Endocr Relat Cancer 2007;14:791-8.

98 Quintavalle C, Mangani D, Roscigno G, et al. MiR-221/222 target the DNA methyltransferase MGMT in glioma cells. PLoS One 2013;8:e74466.

$99 \mathrm{Li} P, \mathrm{He} Q \mathrm{Y}$, Luo CQ, et al. Circulating miR-221 expression level and prognosis of cutaneous malignant melanoma. Med Sci Monit 2014;20:2472-7.

100 El-Garem H, Ammer A, Shehab H, et al. Circulating microRNA, miR-122 and miR-221 signature in Egyptian patients with chronic hepatitis $C$ related hepatocellular carcinoma. World I Hepatol 2014;6:818-24.

101 Pu XX, Huang GL, Guo HQ, et al. Circulating miR-221 directly amplified from plasma is a potential diagnostic and prognostic marker of colorectal cancer and is correlated with p53 expression. J Gastroenterol Hepatol 2010;25:1674-80. 